\title{
O significado da maternidade e seus reflexos para o processo de vida da adolescente-mãe
}

\author{
Elisa Pacheco*, Clara Andréia*, Juliana Lacerda*, Aline Ramos de Carvalho Pinto, M.Sc.**, \\ Verônica Caé da Silva***
}

*Enfermeiras, graduadas na Universidade do Grande Rio (Unigranrio), **Docente da Escola de Ciências da Saúde da Unigranrio, Enfermeira da Clínica Cirúrgica do HEAPN ${ }^{* * *}$ Especialista em Saúde Coletiva, Residência em Saúde do adolescente pela UERJ, Docente da escola de Ciências da Saúde da Unigranrio

\section{Resumo}

Estudo descritivo exploratório com abordagem qualitativa que tem como objetivos: conhecer o significado da maternidade para a adolescente e identificar as mudanças na vida da adolescente advindas da maternidade. As depoentes foram adolescentes primíparas, selecionadas no alojamento conjunto de um hospital público de emergência do Rio de Janeiro. A entrevista foi realizada através de visita domiciliar previamente agendada, no período de pós-parto tardio. Com base na análise de conteúdo, o agrupamento das informaçóes deu origem a três categorias temáticas: 1) O significado da maternidade - para as depoentes a maternidade é permeada pela relação de afeto e apego entre o binômio mãe-filho, fazendo parte desta fase a maternagem; 2) Mudanças na adolescência geradas pela maternidade - reconhecem que a maternidade acarreta mudanças em sua vida, em virtude das exigências incorporadas; 3) A relação de afeto presente no binômio mãe-filho - torna-se evidente a relação prazerosa desencadeada pelo contato máe-bebê, apontando um precoce amadurecimento para assumir o cuidado do filho a partir da presença do concepto. Sendo assim, reconhecemos que os aspectos subjetivos da maternidade para estas adolescentes contribuirão para um direcionamento na assistência a estas mulheres.

Palavras-chave: adolescente, gravidez, afeto, enfermagem.

\section{Abstract \\ Motherhood meaning and changes in adolescent mother's life}

The objective of this descriptive exploratory study with qualitative approach was to know the meaning of motherhood for adolescent girl and identify changes in the adolescent mother's life. The participants were primiparous adolescents and were selected from a rooming-in of an emergency public hospital of Rio de Janeiro. The interview was conducted through domiciliary visits which were scheduled in advance, during late post-partum. Based on content analysis, the data resulted in three thematic categories: 1) The meaning of motherhood - for the adolescent mothers, motherhood is expressed with feelings and affection between mother and child, which is called mothering; 2) Changes in adolescence due to motherhood - they recognize that motherhood means changes in their life, as new demands are incorporated; 3) The mother and son affection - it is clear the pleasant mother-infant relationship, showing an early maturity to take care of the child. Thus, we recognize that the subjective aspects of motherhood for these young people will help to manage the care of these women.

Key-words: adolescent, pregnancy, affection, nursing. 


\section{Resumen \\ El significado de maternidad y sus reflejos para el proceso de vida de la madre adolescente}

Estudio exploratorio descriptivo con enfoque cualitativo que tiene como objetivos: conocer el significado de la maternidad para la adolescente e identificar los cambios en la vida de las madres adolescentes. Participaron en entrevistas adolescentes primíparas seleccionadas de un alojamiento conjunto de un hospital de urgencias público de Rio de Janeiro. Las entrevistas fueron realizadas durante visita domiciliaria programadas con antelación, en el periodo posparto. Basado en el análisis de contenido, el agrupamiento de datos dio lugar a tres categorías temáticas: 1) El significado de la maternidad - para las madres adolescentes es la relación de afecto y apego entre la madre y el niño, que hace parte de la etapa maternaje; 2) Cambios en las adolescentes a consecuencia de la maternidad - reconocen que la maternidad implica cambios en su vida, en virtud de las exigencias incorporadas; 3) La relación de afecto madre-hijo - es evidente la sensación agradable originada por el contacto madre-hijo, lo que indica una madurez temprana para cuidar al nińo en la presencia del concepto. Por lo tanto, reconocemos que los aspectos subjetivos de la maternidad para estas adolescentes jóvenes ayudaran a orientar la asistencia a esta mujer.

Palabras-clave: adolescente, embarazo, afecto, enfermería.

\section{Introdução}

A adolescência é uma fase de transição entre a infância e a vida adulta caracterizada por alteraçóes físicas, psíquicas e sociais. Essas alteraçóes são acompanhadas pelas mudanças comportamentais e pela construção dos papéis sociais, constituindo os processos inerentes a evolução de cada ser, na qual a consolidação do crescimento e do desenvolvimento dos indivíduos como cidadãos culminam com a conquista dos direitos e deveres dentro da sociedade.

A responsabilidade para assumir seus atos e a possibilidade de se projetar socialmente não é determinada por uma idade cronológica, mas pelo desenvolvimento da maturidade psicossocial, que é influenciada pelo contexto no qual o adolescente está inserido.

Dentre a diversidade das transformaçóes associadas ao processo de desenvolvimento social e corpóreo, caracterizado pela adolescência, destacamos a sexualidade aflorada, potencializada pela explosão dos hormônios sexuais que contribuem para a aproximação dos sexos opostos, e conseqüentemente para a iniciação da vida sexual.

Durante as atividades acadêmicas de ensino da prática clínica na disciplina de Saúde da Mulher III, desenvolvidas em um hospital estadual do Rio de Janeiro, tido como referência para o atendimento a gestantes de alto risco, foram desenvolvidas diversas atividades, entre as quais, prestar assistência à mulher no ciclo gravídico-puerperal, desde sua admissão no início do trabalho de parto, passando pela evolução das diferentes etapas clínicas até o puerpério. Nesta atividade prática, o elevado número de gestantes adolescentes, entre 12 e 19 anos, que davam entrada no hospital chamou nossa atenção, de modo que, quando realizávamos o atendimento admissional a estas pacientes, freqüentemente constatávamos a inexistência do acompanhamento pré-natal.

De modo empírico, buscávamos as razóes pelas quais estas adolescentes não se dirigiam ao serviço de saúde a fim de buscar informaçóes e realizar o acompanhamento da gestação. Dentre os possíveis fatores, percebíamos que, na maioria dos casos, existia uma interdependência entre as condições de imaturidade, tanto para gerar quanto para conceber e, principalmente, para maternar.

Esta percepção corrobora com os diferentes estudos que já observaram os diversos riscos da gestação na adolescência, principalmente aqueles relacionados aos aspectos anátomo-fisiológicos, além dos fatores inerentes a imaturidade para identificar o novo papel social e assumi-lo, o que justificaria a fuga imediata durante a constatação da gravidez e a aceitação tardia do ser concebido.

Desta forma, podemos verificar a validade dos estudos que propuseram que a maternidade não se vincula apenas às atividades de zelar pela saúde corpórea dos próprios filhos, sendo também responsável pelo processo educacional destes indivíduos dependentes, e que a gravidez na adolescente provoca diversas emoçóes contraditórias, de forma que a aceitação desta gestação será o diferencial no processo de maternagem [1].

"A maternagem é a relação de apego entre mãe e bebê, interação entre dois seres unidos fisicamente e afetivamente" [1]. Por outro lado, Winnicott afirma que "o conceito de maternagem pode ser compreendido como o conjunto de cuidados dispensados ao bebê que visa suprir suas necessidades" [2]. 
O sentimento de maternidade, desenvolvido diferentemente por cada grupo social, em momentos diferentes, transcende as questóes biológicas, impondo interaçóes com os aspectos culturais desta mãe adolescente, e gerando alteraçóes na construção das relaçóes afetivas entre mãe e bebê, ainda que as questóes da maternagem perpassem, de formas aleatórias, pelo processo de desenvolvimento da maternidade.

Julgamos importante identificar a capacidade da adolescente-mãe reconhecer esta relaçáo de apego e interação como parte da maternidade.

A partir destas consideraçóes surgiu o interesse em investigar o significado da maternidade e seus reflexos para o processo de vida da adolescente-máe.

Elegemos como objetivos:

- Conhecer o significado da maternidade para a adolescente.

- Identificar as mudanças reconhecidas pela adolescente advindas da maternidade.

- Apresentar reflexóes sobre os cuidados de enfermagem a serem prestados às adolescentes gestantes, que favoreçam ao processo de vida da adolescente.

\section{Material e métodos}

Trata-se de um estudo com abordagem qualitativa descritiva do tipo exploratória. As abordagens qualitativas abarcam a totalidade de seres humanos, concentrando-se na experiência humana em cenários naturistas [3].

De acordo com Minayo, a pesquisa qualitativa surge diante da impossibilidade de investigar e compreender, por meio de dados estatísticos, alguns fenômenos voltados para a percepção, a intuição e a subjetividade. Está direcionada para a investigação dos significados das relaçóes humanas, em que suas açóes são influenciadas pelas emoçóes e/ou sentimentos aflorados diante das situaçóes vivenciadas do dia-a-dia [4]. O cenário do estudo foi um hospital de grande porte situado no município de Duque de Caxias, administrado pela Secretaria Estadual de Saúde do Rio de Janeiro (SES), sendo referência para o atendimento ao trauma e maternidade de alto risco. A escolha se deu pela proximidade das pesquisadoras com a referida instituição, que serviu de campo para estágio acadêmico.
Os sujeitos do estudo foram mães adolescentes (mulheres entre 12 e 18 anos de idade), primíparas, considerando que vivenciaram pela primeira vez a maternidade, sem influência de experiências anteriores. Determinamos como critério de exclusáo, as adolescentes que sofreram a interrupçáo do processo da maternidade (natimorto e neomorto), e/ ou que desenvolveram algum distúrbio psicológico pós-parto.

Para coleta de dados foi utilizado um roteiro de entrevistas semi-estruturado e, as entrevistas foram gravadas em MP3 e transcritas pelas autoras. Essa entrevista requer a elaboração de questionamentos básicos, apoiados nas questóes e teorias descritivas no estudo, de forma a oferecer um amplo campo de interrogativas, que surgem à medida que se recebe as informaçóes do sujeito da pesquisa [5].

Os dados foram coletados durante a visita domiciliar (VD) ocorrida no segundo semestre de 2008. A seleção das depoentes foi realizada junto ao setor alojamento conjunto da referida instituiçáo, onde foram previamente agendadas (data e hora) as VD's com os sujeitos.

A coleta de dados foi realizada com 7 mães no puerpério tardio, entendendo que neste período a adolescente já se apresenta inserida no contexto da maternidade.

Respeitaram-se os princípios ético-legais, sendo o estudo submetido à aprovaçáo do Comitê de Ética da Unigranrio, incluindo solicitação de consentimento a instituição e a assinatura do termo de consentimento livre e esclarecido pelas depoentes de acordo com a resolução 196 de 10 de outubro de 1996.

Após a transcrição das entrevistas, as informaçóes foram submetidas a leituras intensivas, e a análise de dados foi realizada por ensaios categóricos, com base na análise de conteúdo. Por meio da análise de conteúdo, podemos encontrar respostas para as questóes formuladas e também podemos confirmar ou não as afirmaçóes estabelecidas antes do trabalho de investigação. Este tipo de análise também permite “a descoberta do que está por trás dos conteúdos manifestos, indo além das aparências do que está sendo comunicado" [6].

Cabe ressaltar que os nomes das entrevistadas foram substituídos por codinomes de flores, de forma aleatória, com o propósito de garantir o seu anonimato. 
Resultados e discussão

\section{$1^{\text {a }}$ categoria: o significado da maternidade}

Quando interrogadas sobre o que é ser mãe, as entrevistadas apresentam em seus discursos um sentimento de maternagem como parte da maternidade, prevalecendo a relação de amor, afeto e apego, ou seja, o vínculo do binômio mãe-filho se mantém presente.

“[...] é uma coisa inexplicável porque o amor que agente sente pelo nosso filho é diferente de qualquer outra coisa." (Azaléia)

"[...] ser mãe, pra mim é um ato de amor, carinho e muita responsabilidade." (Lírio)

"[...] é uma experiência muito importante que houve na minha vida, uma coisa muito especial." (Orquídea).

Percebe-se um despertar do instinto materno, a maternidade embutida de maternagem exige inúmeros aprendizados, pois neste sentido encontra-se implícito o significado de cuidar, requerendo zelo, afeto, projeção, e para que este vínculo mãe-filho ocorra primeiramente, faz-se necessário assumir o seu novo papel de máe, pois isto favorece a fase de adaptaçóes, e o aprendizado para cuidar da criança. A capacidade para cuidar pode ser desenvolvida, despertada ou inibida através da experiência educacional. Consideramos que a fase de apego e afeto desenvolvidos na relação mãe-filho, a partir do conhecimento do ser que cuida para o ser que é cuidado, pode influenciar positivamente para o processo de maternagem [7].

Castro [8] acredita que o "amadurecimento precoce” da máe-adolescente sofra influência de experiências diferentes de vida que vão se alinhavando no decorrer do processo de desenvolvimento, o que de certo modo foge aos preceitos descritos nas teorias psicológicas da adolescência. Considera-se que esta maturidade tenha influência dos fatores ambientais e sócio-culturais que essas jovens estão inseridas.

Acreditamos que todos esses aspectos são relevantes no processo da maternagem, considerando também as experiências vividas, os aspectos sócioculturais, os familiares e os ambientais em que as adolescentes encontram-se inseridas, e que a relação do binômio mãe-filho é influenciada pela aceitação desta mulher ao seu novo papel.
Contudo podemos identificar em alguns discursos a sobrecarga gerada pela maternidade na adolescência.

"[...] é um pouco mais de estresse, um pouco. Ah! Ser mãe dá trabalho mesmo, criança é cuidado, é difícil, ainda mais eu, que sou inexperiente. Primeiro filho é difícil.” (Violeta)

"É ser duas em uma." (Flor do Campo)

Tornar-se mãe é, para a adolescente, um grande desafio, principalmente por ser uma fase carregada de transformaçóes e instabilidades; transformaçóes que se voltam para as mudanças de atitudes, de comportamentos, de relação, e ainda sob os reflexos da gestação no seu corpo em transformação, e instabilidades geradas pelas responsabilidades imputadas a esta adolescente a fim de garantir o cuidado com o seu filho, sendo que na maioria dos casos, ela assume a criação da criança sem a presença da figura paterna.

Evidentemente, a situação vivenciada pelas adolescentes é sustentada pelo nível de ansiedade, sentimentos de impotência e até mesmo imaturidade, relacionado à inexperiência do cuidado, pois, a mãe foi promovida à "grande responsável" pela felicidade de seu rebento [1].

Nesse sentido Andrade [9] salienta que “(...) as mães-adolescentes se sentem cada vez mais exigidas e mais cansadas, porque grande parte de seu tempo é direcionado aos cuidados do bebê. O cansaço acumulado, por vezes, dificulta o cuidar e esta dificuldade geralmente está relacionada ao fato de acordar de madrugada para amamentar e trocar o bebê." Isto se torna evidente no discurso de Lírio, transparecendo um sentimento de impaciência da mãe-adolescente pelas solicitaçóes freqüentes do recém-nascido, o que lhe causa cansaço mental e físico.

\section{$2^{a}$ categoria: mudanças na adolescência geradas pela maternidade}

As mães adolescentes foram unânimes ao apontarem as mudanças geradas pela maternidade, ora referindo-se a sua vida social e de relação, ora a responsabilidade imposta pela maternidade, exigindo a maturidade.

“[...] mais responsabilidade, maturidade, mais ordem na minha vida, mais importância." (Orquídea) 
“[...] houve tudo, não posso sair, não posso mais me divertir, não posso nada, é porque agora tenho filho, tenho que ficar cuidando dele direto." (Margarida)

"[...] As pessoas cobram mais, antigamente ninguém me cobrava nada, agora me cobram, se faço alguma coisinha errada, já falam que vou dar mau exemplo pro meu filho." (Violeta)

"[...] minha máe sempre me tratou com bastantes mordomias, algumas coisas mudaram, as coisas que ela deveria comprar pra mim, ela começou a comprar para meu filho, não conseguia dormir direito, evitava de sair. Infelizmente as amizades mudaram bastante." (Lírio)

"[...] saía muito, hoje em dia vivo só pra minha filha, não saio, abri mão de muitas coisas pra viver só para ela." (Flor do Campo)

Nos discursos, por vezes, identificamos uma "responsabilidade" imposta por outras pessoas, em outros momentos, as mudanças ocorridas são advindas da maturidade e do reconhecimento em assumir seu novo papel. Embora as máes adolescentes reconheçam as mudanças geradas pela maternidade, o comportamento de aceitaçáo, negação, ou revolta terá influência de todo o contexto vivido, e suas características pessoais.

Para Meleis [10], a adolescência e a gestação são vistas como eventos de transição, e que comumente desencadeiam uma crise existencial na vida das pessoas. A mesma autora considera que a adolescente puérpera encontra-se em uma mediação entre assumir o novo papel e adaptar-se a ele, está em transiçáo. Para evoluir de um estado a outro necessita o envolvimento e suporte de todos os envolvidos, em especial da família, por ter maior afinidade ou significantes, pessoa próxima em quem deposita confiança e tem alianças afetivas, para que juntos possam enfrentar esse período de transição.

Sendo assim, identificamos que ocorreram mudanças significativas na vida das adolescentes após a gravidez, visto que sua rotina foi alterada devido à sua nova condição, que é ser mãe. De certo modo, ela vivencia uma dupla transição, a de ser adolescente, vivenciando um período de mudanças corporais e emocionais, e a de estar grávida, com a subseqüente maternidade, quando as mudanças se intensificam até a aquisição do seu novo papel, com as cobranças sociais derivadas desta situação.
Nazareth [11] descreve que

“(...) a gravidez seria um período de crise
normal de desenvolvimento, é claro se ocor-
resse no tempo certo e não num momento
onde as soluçóes encontradas poderão cul-
minar em uma maior maturidade ou então
a um grau de desintegração, desorganização
e desajustamento da personalidade. (...) o
ser adolescente puérpera ao referir-se à tran-
siçáo situacional da ocorrência da gestação
nessa fase da vida expressa como sendo um
processo de significativas mudanças, as quais
denotam uma ambivalência de sentimentos
positivos e negativos. A vivência da gestação
é tida como maravilhosa, prazerosa, de feli-
cidade apesar de considerar-se muito jovem
para essa experiência."

\section{$3^{\text {a }}$ categoria: a relaçáo de afeto presente no binô- mio mãe-filho}

Embora a gravidez das adolescentes entrevistadas não fosse planejada, observou-se a partir dos discursos que a presença do concepto desperta neste ser mãe o instinto maternal desenvolvendo o apego/afeto.

"[...] não dou de mamar, mais eu gosto dos meus filhos, sinto uma coisa diferente. [...]" (Margarida)

"[...] quando brinco com meu filho, eu me sinto muito feliz, uma coisa diferente, diferente mesmo, porque além de eu ser nova e ter essa experiência importante que vou ter que levar pro resto da minha vida. [...]" (Orquídea)

É notável a relação prazerosa desencadeada pelo contato mãe-bebê, existindo uma demonstração de apreço. Apesar do trabalho que demanda, as máes adolescentes mostram-se preocupadas e zelosas, sentem-se responsáveis em suprir as necessidades do recém-nascido, desenvolvendo um precoce amadurecimento para assumir o cuidado do filho.

Em um estudo realizado por Folle \& Geibe [12] sobre a representação dos recém-nascidos pelas mães adolescentes, identificou-se que o recém-nascido representa para a mãe uma gama de sentimentos positivos, considerando-o a extensão da sua própria 
vida, e é o responsável direto, tanto pela motivação renovada e pelo crescimento psicológico, quanto pelo processo de amadurecimento materno, que as faz perceber o compromisso da maternidade. O bebê é tido como fonte de felicidade, de amadurecimento saudável e de apropriação legítima.

Do mesmo modo, em pesquisa relatada por Mazzini [13], foi verificado que após o nascimento do filho, as adolescentes experimentaram uma multiplicidade de sentimentos. Quando abordadas sobre os sentimentos que emergiram no primeiro contato estabelecido com o bebê, a maior parte confirmou a prevalência de sentimentos positivos, sendo eles de alegria, de felicidade e de curiosidade. Porém, uma mãe relatou sentimento negativo de medo. Após a normalização do processo involutivo do puerpério, relataram a superação das suas dificuldades e perceberam a maternidade como sendo parte de suas vidas, confirmando, em seu discurso, o prazer de ser máe.

Podemos destacar que esta prevalência de sentimentos positivos na relaçáo mãe-filho no puerpério, pode ser dificultada em uma maternidade, devido ao curto espaço do tempo de permanência naquele ambiente, onde não seria possível interferir efetivamente sobre o despertar destes sentimentos durante a sala de admissão, o parto e até mesmo no puerpério. Compreendendo que esta relação positiva se desenvolve com a presença do recémnato, por meio do contato, desencadeando afeto, zelo e apego, acreditamos que para favorecer o desenvolvimento instintivo da maternagem, os profissionais de saúde devem privilegiar a fase do apego, o mais precocemente possível, a fim de minimizar problemas relativos ao cuidado, tendo o medo como exemplo.

Apesar de a ambivalência de sentimentos, descobertas, dificuldades e aprendizados, desta nova fase, o sentimento positivo se sobrepóe, deixando transparecer sua felicidade e satisfação ao cuidar do filho.

Identificamos ainda que em alguns momentos, as mudanças impostas pelo papel de mãe podem despertar na adolescente uma relação de conflito.

"[...] não vou falar que é raiva, sinto uma coisa muito boa porque é meu filho saiu de mim, dou carinho e tudo mais, mais a consciência pesa um pouco, porque sou nova e não era hora. [...]" (Lírio)
Podemos perceber que a gestação é vivida com intensa angústia e poderosos bloqueios afetivos, não tendo a gestante maturidade emocional para estabelecer um vínculo saudável com o bebê.

De acordo com o discurso observado, a adolescente-máe manifesta uma relaçáo de conflito diante de sua condição, associado à transição própria de sua fase como uma época de desordem e desequilíbrio, bem como de satisfação.

Para Zagonel et al. [14], a adolescência e a gestaçáo são vistas como eventos de transição, dois momentos marcantes que podem desencadear uma crise existencial na vida do ser humano que a vivencia, são eventos marcados por períodos de euforia, deslumbramento e realização, como também ansiedade, desequilíbrio, estresse físico e emocional. Transitar rumo ao papel materno possibilita à adolescente transpor barreiras e momentos agradáveis, portanto, felizes, próprios da adolescência, simultaneamente a vivência de transição gestacional, para entáo assumir o papel materno.

Percebemos através desse discurso que a adolescente ama seu filho, contudo atravessa um momento de intensa angústia, em que faz uma análise desta condição gerada pela maternidade ocorrida de forma inesperada e imatura, evidenciando que, mesmo se projetando para a maternagem, a adolescente reconhece as mudanças impostas e, ainda assim, supera tensóes que podem gerar conflitos psicossociais.

Náo obstante, podemos inferir que o acompanhamento pré-natal exerce motivaçáo preponderante para a consolidação da maternidade e a aceitação dos novos papéis sociais a serem desempenhados pela adolescente, bem como se torna fundamental para o desenvolvimento efetivo da maternagem nos momentos iniciais do puerpério.

\section{Conclusão}

Através deste estudo, em um pequeno universo, pudemos identificar que a maternidade impóe mudanças bio-psico-sociais na vida da adolescente, sendo estas reconhecidas pelas entrevistadas. Destacamos que o aspecto biológico é o menos relevante, tendo em vista que a ênfase concedida pelas adolescentes são as transformaçóes sociais desencadeadas ao assumir o seu papel de mãe.

Deste modo, a maternidade desencadeia reaçóes que podem se manifestar de formas diferentes, considerando a história de vida de cada adolescente, bem como a maturidade para vivenciar esta fase de 
transição. Sob esta ótica, destacamos a importância do enfermeiro como o profissional que pode minimizar as dificuldades relativas a esta fase de adaptação, promovendo uma relação de vínculo e confiança com a adolescente e família durante a assistência prestada no ciclo gravídico-puerperal.

Ressaltamos que embora nos discursos se encontrem explícitos os conflitos psico-sociais vivenciados, é notável o sentimento maternal que aflora com a presença do concepto. Identificamos, ainda, que a capacidade para cuidar fora desenvolvida e despertada pela fase do afeto/apego, prevalecendo sentimentos positivos, na qual o contato mãe-bebê estabelece uma relação prazerosa.

Este estudo servirá de incentivo a novas pesquisas, tendo em vista a relevância de se considerar os aspectos subjetivos da maternidade para os familiares, sociedade e pelo profissional que presta o atendimento a esta adolescente no ciclo gravídico puerperal, reconhecendo que estes aspectos devem ser considerados para um direcionamento na assistência a esta mulher.

Acreditamos que a partir da valorização dos sentimentos e expressóes destas adolescentes a enfermagem poderá atuar de forma mais eficiente, ampliando a sua abordagem além dos aspectos técnicos, e buscando contemplar as necessidades a partir de uma visão holística. Para isto se faz necessário a sensibilização do profissional, pois este poderá influenciar positivamente na relação de apego/afeto mãe-bebê.

Cabe ressaltar que a enfermagem é um facilitador no desenvolvimento da relação com a família, que apresenta um grande papel neste processo. Percebemos que através da confiança, segurança, estímulo, que são fatores que contribuem na construção de um ambiente favorável, se processa a base desta relação.

\section{Referências}

1. Badinter E. Um amor conquistado: o mito do amor materno. Rio de Janeiro: Nova Fronteira; 1985.

2. Winnicott DW. Os bebês e suas máes. São Paulo: Martins Fontes; 1999.

3. Wood GL, Haber J. Pesquisa em Enfermagem: métodos, avaliação crítica e utilização. $4^{\mathrm{a}}$ ed. Rio de Janeiro: Guanabara Koogan; 2001.

4. Minayo MCS, ed. Pesquisa social: teoria, método e criatividade. Rio de Janeiro: Vozes; 1994.

5. Figueiredo NMA. Método e metodologia na pesquisa científica. 2a ed. São Paulo: Yendis; 2007.

6. Minayo MCS, Ed. Pesquisa social. Rio de Janeiro: Vozes; 2000.

7. Waldow VR. Cuidar/cuidador: o domínio unificador da enfermagem. In: Waldow VR, Lopes MJM, Meye DE. Maneiras de cuidar maneiras de ensinar: a enfermagem entre a escola e a prática profissional. Porto Alegre: Artes Médicas; 1995.

8. Castro V. Consideraçóes a respeito da adolescência [online]. [citado 2008 Out 4]. Disponível em URL: http//www.vaniadecastro.com.br.

9. Andrade PR. Superando dificuldades impulsionadas pela força do amor: a experiência da mãe adolescente vivenciando o cuidado do filho [dissertação]. São Paulo: Escola Paulista de Medicina, Universidade de São Paulo; 2004.

10. Meleis AI. Theoretical nursing: development and progress. 3 ed. Philadelphia: Lippincott; 1997. p.108.

11. Nazareth ER. O mito do amor materno. Rio de Janeiro: Vozes; 2004

12. Folle E, Geib LTC. Representaçôes sociais das primíparas adolescentes sobre o cuidado materno ao recémnascido. Rev Latinoam Enfermagem 2004;12(2):18390.

13. Mazzini MLH. A construção da identidade materna na adolescente grávida [dissertação]. Faculdade de Filosofia Ciências e Letras de Ribeirão Preto, Universidade de São Paulo; 2003.

14. Zagonel IPS, Martins M, Pereira KF, Athayde J. O cuidado humano diante da transição ao papel materno: vivências no puerpério [online]. Revista Eletrônica de Enfermagem 2003;5(2):24-32. 